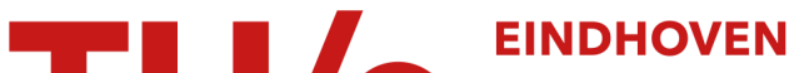 \\ UNIVERSITY OF \\ TECHNOLOGY
}

\section{Modelling the dynamics of technological innovation systems}

Citation for published version (APA):

Walrave, B., \& Raven, R. P. J. M. (2016). Modelling the dynamics of technological innovation systems. Research Policy, 45(9), 1833-1844. https://doi.org/10.1016/j.respol.2016.05.011

DOI:

10.1016/j.respol.2016.05.011

Document status and date:

Published: 01/01/2016

Document Version:

Accepted manuscript including changes made at the peer-review stage

Please check the document version of this publication:

- A submitted manuscript is the version of the article upon submission and before peer-review. There can be important differences between the submitted version and the official published version of record. People interested in the research are advised to contact the author for the final version of the publication, or visit the $\mathrm{DOI}$ to the publisher's website.

- The final author version and the galley proof are versions of the publication after peer review.

- The final published version features the final layout of the paper including the volume, issue and page numbers.

Link to publication

\section{General rights}

Copyright and moral rights for the publications made accessible in the public portal are retained by the authors and/or other copyright owners and it is a condition of accessing publications that users recognise and abide by the legal requirements associated with these rights.

- Users may download and print one copy of any publication from the public portal for the purpose of private study or research.

- You may not further distribute the material or use it for any profit-making activity or commercial gain

- You may freely distribute the URL identifying the publication in the public portal.

If the publication is distributed under the terms of Article $25 \mathrm{fa}$ of the Dutch Copyright Act, indicated by the "Taverne" license above, please follow below link for the End User Agreement:

www.tue.nl/taverne

Take down policy

If you believe that this document breaches copyright please contact us at:

openaccess@tue.nl

providing details and we will investigate your claim. 


\title{
Modelling the dynamics of Technological Innovation Systems
}

\author{
Bob Walrave*, Rob Raven+ \\ * Eindhoven University of Technology, School of Industrial Engineering, Eindhoven, The \\ Netherlands \\ + Utrecht University, Copernicus Institute, Utrecht, The Netherlands
}

ACCEPTED FOR PUBLICATION IN 'RESEARCH POLICY'

\begin{abstract}
Currently there is no formal model describing the dynamics of technological innovation systems. This paper develops a system dynamics model that integrates the concept of 'motors of innovation', following the literature on emerging technological innovation systems, with the notion of 'transition pathways' that was developed as part of the multilevel-framework thinking. As such, the main contribution of this paper is a cross-over of two key-frameworks into a system dynamics model that can serve as underpinning for future research. The model's behaviour is illustrated by means of analyses of TIS dynamics in the context of different transition pathways, under different resourcing conditions. The paper also provides a future research agenda, pursuable by means of experimentation and/or further development of the presented model.
\end{abstract}

Keywords: technological innovation systems, multi-level perspective, TIS-MLP, system dynamics model, sustainability transitions. 


\section{Introduction}

Present-day societies are facing grand societal challenges such as dealing with climate change, depletion of natural resources and aging societies. Incremental changes such as improving production efficiencies or introducing end-of-pipe solutions to existing sociotechnical systems are no longer sufficient. Increasingly, it is recognised that entire production and consumption systems need to change in order to be able to deal with these challenges. Questions on how such system innovations, or socio-technical transitions, come about, and how interventions in the context of transitions can be organised, are at the heart of a relatively young field of research called sustainability transitions (Markard et al., 2012).

Whilst this field has been expanding its conceptual orientation over the past years, two conceptual frameworks have continued to structure debates and analyses in this field. These are technological Innovation systems (Bergek et al., 2008a; Hekkert et al., 2007; Jacobsson and Bergek, 2004) and the multi-level perspective' (Geels, 2002; Rip and Kemp, 1998). Through numerous empirical analyses of past and on-going transformations in sociotechnical systems, and analysis of emerging innovative configurations, substantial understanding has been reached in the patterns and mechanisms that influence the direction and scope of transformative change. In parallel, possible governance approaches were discussed under headings such as Reflexive Governance (Smith et al., 2005; Voss et al., 2006), Transition Management (Loorbach, 2010; Rotmans et al., 2001) and Strategic Niche Management (Kemp et al., 1998; Schot and Geels, 2008; Smith and Raven, 2012; Raven et al., 2016).

Currently the application and development of these analytical frameworks and governance perspectives are dominated by qualitative case approaches. Whilst some notable exceptions exist (Holtz et al., 2015; Halbe et al., 2015; Lopolito et al., 2013; Holtz, 2011), few have explored the use of formal, modelling approaches to understand the ways in which socio-technical systems transform. While modelling sustainability transitions is challenging due to the complexity and multi-dimensionality of processes involved, we believe that broadening the methodological toolbox of transition scholars is a fruitful direction to explore, not the least because it challenges scholars to articulate and explore causal links between different dynamics of emerging systems more precisely. 
This paper aims to make a contribution to this literature, by developing and exemplifying a new socio-technical transitions model on the basis of a system dynamics approach. It does so by taking outset in the concept of 'motors of innovation', which resonates well with a formal system dynamics model in terms of causal logic and feedback structure (Suurs and Hekkert, 2012; Suurs, 2009) and combines this framework with the notion of 'transition pathways' that was developed as part of multi-level-framework thinking (Geels and Schot, 2007). As such, the paper makes an important contribution to the field by developing a formal model that makes a crossover between the two keyframeworks. Whilst this has been argued to have potential major benefits (Markard and Truffer, 2008; Weber and Rohracher, 2012), few have paused to consider these relationships in more detail.

The research question that this paper aims to address is: "How do technological innovation systems emerge (or decline) in the context of various socio-technical transition pathways?". This question is addressed through the following paper structure. The next section positions the paper in the existing literature on technological innovation systems, the multi-level perspective and modelling approaches to socio-technical transitions. Section 3 continues with the description of the modelling approach taken in this paper. Section 4 presents a discussion on the workings of our model through analyses of TIS dynamics in the context of different transition pathways and under different resourcing conditions. Section 5 follows with a discussion, conclusion and outlook.

\section{Modelling technological innovation systems}

Although the wider sustainable development community is certainly not a stranger to modelling approaches (Club of Rome, 1972), the sustainability transitions community has only recently started to look into the possibilities of more formal approaches. ${ }^{1}$ One of the first pioneering attempts to develop a model to capture multi-level dynamics of socio-

\footnotetext{
${ }^{1}$ The sustainability transitions community is not a clear-cut boundary that can be drawn around
} modelling exercises. We do not attempt to cover the full area of modelling here, but more or less follow Holtz (2011) in his definition of the field. In short, here we are particularly interested in models that take outside in modelling Technological Innovation Systems and the Multi-Level-Perspective, or have been substantially influenced in their design by these frameworks. 
technical transitions occurred in the context of the EU-MATISSE project (Bergman et al., 2008; Köhler et al., 2009; Rotmans et al., 2008). The model builds on agent-based modelling techniques with some elements of system dynamics, and attempted to reconstruct four historical case studies. The model, it was concluded, was quite an innovative heuristic in capturing the generic dynamics of interactions between niches, regime and landscape dynamics, but it turned out to be challenging to model the different pathways in a way that represented the historical narratives developed in historical case studies.

More generally, several reviews of modelling exercises for sustainability transitions have been published since 2011, indicating an emerging research community (Holtz et al., 2015). These reviews indicate the importance of reducing the scope of transition models, that is, to focus a model on parts of the overarching transition dynamic, to improve the likelihood of a good model performance, as well as show the need for sensitivity analysis in order to test the effects of 'accessary assumptions' (Holtz, 2011). Safarzyńska et al. (2012) argue that evolutionary theory and existing evolutionary models may be a good starting point for analysis of system innovations and socio-technical transitions, given that transition frameworks such as the multi-level perspective already built upon evolutionary theorizing (Nill and Kemp, 2009; Schot and Geels, 2007). Finally, Halbe et al. (2015) conclude, among other things, that the agenda on transitions modelling can be brought forward by combining higher-level abstract frameworks such as the multi-level perspective, with frameworks understandings of lower-level abstractions in order to guide modelling frameworks and make them more comparable.

We believe that building upon the literature on technological innovation systems is a promising way in which to proceed with the modelling agenda in the transitions community. Notably, despite its visibility in the transition studies literature, to our knowledge no attempts have been made yet to model the dynamics of technological innovation systems. This is surprising, given that the framework has progressed in quite sophisticated understandings of the ways in which different processes, or functions, influence each other, and how these interactions shape the emergence of new innovation systems. These provide a good starting point for a modelling exercise, given that many of its underlying causal relationships and feedback structures have already been spelled out in quite some detail, and tested in a large variety of case studies. In this respect, the technological innovation systems framework has all the ingredients that connect well to the development of a formal 
model. At the same time, modelling technological innovation systems holds potential to bring forward our understanding of the complex behaviours that follow from the intricate relationship and dynamics.

The approach of technological innovation systems has been discussed elsewhere in elaborate terms (Bergek et al., 2008a; Hekkert et al., 2007). In essence, the technological innovation systems literature is concerned with understanding how new innovation systems emerge around technical innovations such as biogas, solar photovoltaic technologies or electric vehicles in order to support the development and diffusion of these innovations. A key aspect of the TIS framework are 'system functions'. Following Hekkert et al. (2007), we recognize 7 different functions: (1) entrepreneurial activities, (2) knowledge development, (3) knowledge diffusion, (4) guidance of the search, (5) market formation, (6) mobilization of resources, and (7) creation of legitimacy. Next to functions, the literature distinguishes between 'structural dimensions'. Structural dimensions refer to networks and relationships between actors (e.g., at the level of networks or individual contacts), institutions (e.g., rules, regulations, customs, routines, etc.) and technological structures (e.g., infrastructures) (Wieczorek and Hekkert, 2012).

There is some confusion in the TIS literature as to how functions relate to structures. Some argue that functions should be understood as 'structure building processes' (e.g., Hillman and Sandén, 2008; Bergek et al., 2008b). In this view, functions are processes that shape the development of structures such as new actors, infrastructures or institutions. Others argue that functions are emergent properties of an innovation system, which can be used in diagnostic ways: "the functions show the state of a specific innovation system in a defined moment of time" (Wieczorek and Hekkert, 2012: 77). We argue that the model in this paper largely adheres to the second view; relations between functions and structures are only modelled at an aggregated level. ${ }^{2}$

2 Functions are systematically operationalised in the model through a combination of 'stocks and flows' which at any point in time can be used to diagnose the state of TIS at that time. The model does not operationalise explicitly how these functions shape the structural dimensions of the TIS. This relationship is only captured on an aggregated level under the label 'TIS structures' (see Figure 2). A next version of the model can be developed to unpack in greater detail the relation between functions and structures. 
A body of literature on technological innovation systems has been concerned with understanding the ways in which interactions between functions shape the development of these innovations. Here, we follow the work from Suurs (2009), Suurs et al. $(2009,2010)$ and Suurs and Hekkert (2012) as a starting point for developing a technological innovation systems model. Suurs (2009) develops hypotheses on how and which kind of these functions influence each other in different phases of innovation system development, so called 'motors of innovation'. More specifically, these authors have developed causal loop diagrams, based on extensive case studies. Such causal reasoning resonates well with the development of a formal system dynamics model, as it contains all the components (e.g., causal logic, delays and feedback structures) required for such exercise (Sterman, 2000).

Four motors of innovation are distinguished. The 'science and technology push motor' refers to patterns in innovation systems in which formal, scientific knowledge development and diffusion are central, supported by R\&D programmes and policy support. This knowledge production and diffusion shapes initial experimental projects and other entrepreneurial activities, which may increase further financial and political support when outcomes confirm initial expectations, or, in turn, may reduce support when the results of these projects are perceived as negative. The key-functions in this motor are "knowledge development', 'knowledge diffusion', 'guidance of the search' and 'resource mobilisation'.

The 'entrepreneurial motor' refers to patterns in innovation systems in which core dynamics are constituted by an increasing number of firms and entrepreneurs becoming active in the innovation system, which increases legitimacy in the eyes of external funders such as governments. There is also ad-hoc advocacy for further external resource provision, for instance by firms aiming for temporary financial support to reduce risks when investing in uncertain projects. Through precarious commercial activities in niche markets, some initial financial resources are also generated internally in the innovation system. These feed back into knowledge development, when for instance feasibility studies or reviews of demonstration projects are published. Hence, learning dynamics constituting this motor are broadening from learning-by-searching to include learning-by-doing. The key-functions in this motor are similar to those in the 'science and technology push motor', but 'entrepreneurial activities' and 'creation of legitimacy' are also strongly present.

The 'system-building motor' is a pattern in innovation system dynamics that is constituted by increasing organisation of actors in networks, infrastructural developments 
and attempts at institutional reconfigurations. The type of actors supporting the innovation system broadens and starts to attract wider societal support (e.g., Bergek et al., 2008b), for instance through the establishment of user communities, or the institutionalisation of policy ambitions in reconfigured regulatory rules, or the construction of physical infrastructures such as a wide-spread network of charging stations for electric vehicles. The system-building motor is socially and politically a particular challenging phase in innovation system developments, as the required resources will increase substantially compared to the 'science and technology push' and 'entrepreneurial' motors, whilst at the same time internally generated resources through market sales are still limited. Organised sustained advocacy over longer time frames is, therefore, considered a key process in this motor. In terms of functions, all functions are important in this motor, but 'market formation' is critical (Suurs, 2009: 219).

When innovation system actors successfully navigate this 'valley of death', an innovation system is argued to be constituted by a 'market motor'. This refers to a pattern in an innovation system that is internally resourced through substantial market demand, which is sufficient for maintaining all necessary processes in the innovation system. Advocacy for the innovation system has institutionalised into hidden patterns of social and political support, and legitimacy of an innovation system is no longer explicitly questioned. In terms of functions, all functions are important in this motor, but 'creation of legitimacy' is less critical (Suurs, 2009: 233).

The technological innovation system approach has been critiqued for having limited conceptual understanding of how an emerging innovation system interacts with its broader environment (Markard and Truffer, 2008; Smith and Raven, 2012), although some conceptual entrance points exist, for instance, through the notions of legitimation (Bergek et al., 2008b) or the notions of blocking and inducement mechanisms (Jacobsson and Bergek, 2004). The interplay between innovation systems and their contexts is important, because technological innovation systems do not emerge in a vacuum, and their fate depends on the ways in which they interact with their wider environment, and the kind of dynamics in that environment. A recent contribution comes from Bergek et al. (2015), who 
distinguish between four kinds of 'contexts' relevant to TIS dynamics. ${ }^{3}$ In our model we contextualise emerging innovation systems with the notion of socio-technical transition pathways (Geels and Schot, 2007). The notions of regime and landscape, as developed in the context of the multi-level perspective, potentially provide fruitful avenues for exploring this interplay between innovation system and context (Markard and Truffer, 2008; Bergek et al., 2015).

Geels and Schot (2007) distinguish between one 'business as usual' situation (referring to a dynamically stable situation, i.e., no transition is occurring) and four different kinds of transition pathways, depending on the timing of interaction between niche, regime and landscape levels and the nature of interaction between a niche and the incumbent sociotechnical regime. Timing of interactions distinguishes between (1) the occurrence of landscape pressures when a niche has not yet substantially developed; and (2) the occurrence of landscape pressures when a niche has substantially developed. ${ }^{4}$ The nature of interactions distinguishes between (1) a competitive relationship between a niche and the existing regime; and (2) a symbiotic relationship between a niche and the existing regime. According to Geels and Schot (2007:406), 'niche-innovations have a competitive relationship with the existing regime, when they aim to replace it. Niche-innovations have symbiotic relationships if they can be adopted as competence-enhancing add-on in the existing regime to solve problems and improve performance'. In this paper we interpret this criterion as follows. In case of a competitive relationship, an existing regime responds to an emerging innovation system by stepping up its efforts to lobby against an emerging TIS (Smink et al., 2013; Geels, 2014) and increase innovative efforts on the dominant socio-technical configuration, for instance through a renewed wave of innovation in the incumbent technology (e.g., environmental efficiency improvements in coal technologies in response to clean tech innovation), or when incumbents cherry pick parts of the emerging innovation

\footnotetext{
${ }^{3}$ These are: 1) interaction between a focal TIS and other TISs; 2 ) interaction between a focal TIS and
} relevant sectors; 3 ) interaction between a focal TIS and its geographical context; 4) interaction between a focal TIS and the political context. The model in this paper includes interactions of the second and fourth type.

${ }^{4}$ Geels and Schot (2007), on the basis of Suarez and Oliva (2005), also distinguish between different kinds of landscape change (regular, hyperturbulance, specific shock, disruptive, avalanche). The model in this paper does not make this distinction for reasons of simplicity, and only models 'specific shocks'. 
system (e.g., co-firing organic waste in coal power plants, see Raven, 2006). The latter is referred to as a so-called 'sailing ship effect' (Adner and Snow, 2010; Cooper and Smith, 1992; Howell, 2002), through which the performance of the incumbent regime is improved in light of the rise of the emerging TIS. The combined effect of lobby efforts against the TIS and innovation efforts in the incumbent regime result in 'regime resistance towards the TIS'. The sailing ship effect thus increases the difficulty of an innovation system to establish itself vis-à-vis the regime. In case of a symbiotic relationship, this sailing ship effect is still present, but significantly more limited as the emerging innovation system experiences less competition with mainstream markets (simply due to their symbiotic nature).$^{5}$

The above translates in the following four transition pathways as contexts for emerging technological innovation systems (see also fig. 1).

- A 'transformation pathway', in which 1) landscape pressures occur at a moment when a technological innovation system has not yet developed substantially; and 2 ) regime resistance is large because regime-actors respond to these pressures by increasing their innovative efforts on the dominant socio-technical design, and only slowly and hesitantly look for innovations beyond regime boundaries.

- A 'de-alignment and re-alignment pathway', in which 1) landscape pressures also occur at a moment when a technological innovation system has not yet developed substantially; but 2) regime-actors lose faith in the existing socio-technical regime and search pro-actively for alternatives, that is, regime resistance is relatively small.

- A 'technological substitution' pathway', in which 1) landscape pressures occur at a moment when a technological innovation system has benefited from previous substantial support and development efforts; and 2) regime-actors continue to support the incumbent socio-technical configuration through innovative efforts.

${ }^{5}$ Note that, conceptually, in both situations the technologies may still initially be developed in a niche. However, TIS growth is considered less challenging in case of a symbiotic relationship, because regime actors are less threatened (or see the TIS as complementary to their core business) compared to a competitive relationship. 
- A 'reconfiguration pathway', in which 1) landscape pressures also occurs at a moment when a technological innovation system is already developed substantially; and 2) regime-actors start adapting (elements of) this innovation system into the existing socio-technical configuration, which implies a relatively low regime resistance.

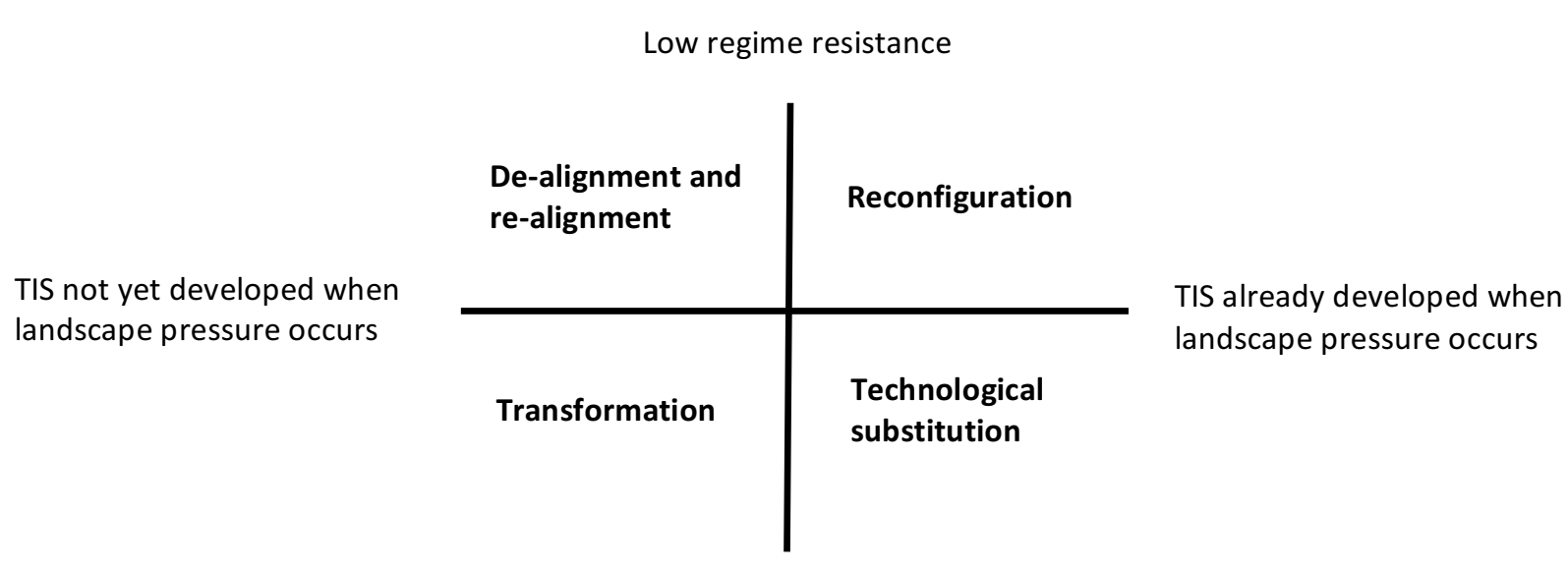

High regime resistance

Figure 1. Four transition pathways.

In the next section we elaborate how we combined these two concepts into a formal model. Subsequently, the model is run to explore TIS dynamics in the context of the four different transition pathways.

\section{Method and model description}

As TIS growth and decline constitute a dynamically complex phenomenon, there is an opportunity to develop a Systems Dynamics (SD) model with respect to their underlying growth and decline processes (Davis et al., 2007; Walrave et al., 2011; 2014). SD models allow for investigating multiple interacting processes and feedback loops, time delays, and other non-linear effects (Sterman, 2000)-characteristics commonly referred to by the transition community. 
Every methodological approach has boundaries and limitations, including formal models. ${ }^{6}$ First of all, in an attempt to keep the model as parsimonious and generic as possible, the model is not attuned to a technology-specific innovation system. We believe this is legitimate given that the TIS approach itself applies generic concepts to study a variety of technological innovations. Second, the model assumes a 'single TIS' - 'single regime' situation. Though this is a simplification of empirical reality in which often multiple TIS compete in the context of multiple regime contexts, this methodological choice is not different from most cases investigated in the transition studies field. Finally, in line with recommendations from former studies (Holtz et al., 2015), and to improve model performance, we focus on only one part of the overarching transition dynamic. More specifically, we aim to replicate the initial growth (and possible decline) of a TIS in the context of a dominant socio-technical regime (rather than modelling a full transition from start to finish).

Due to the SD model's complexity, we provide a description of the model's dynamics, rather than providing a detailed explanation of all equations. A comprehensive description of the model, including equations, units, constants, et cetera, is given in the Model Appendix (which can be obtained directly from one of the authors). Figure 2 provides a stylized overview of the model.

${ }^{6}$ We note that more fundamental ontological and epistemological questions can be asked here too, to which we return in the conclusions. 


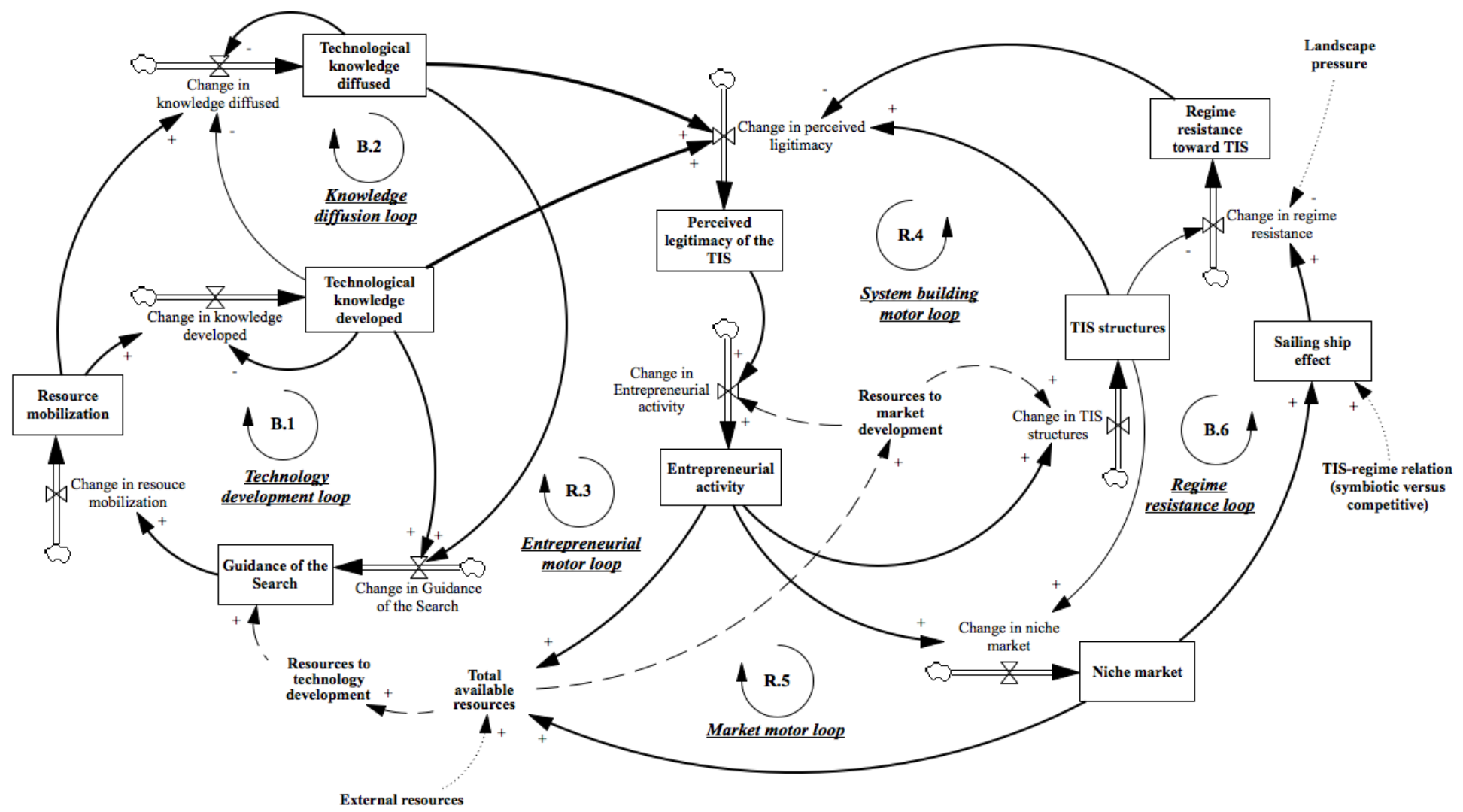

Figure 2. Stylized overview of the system dynamics model.

The main ingredients of system dynamics models are stocks, flows, and variables. In the diagramming notation, stocks are represented by rectangles and denote a particular level (e.g., the amount of technological knowledge developed). Note that for all stocks in the model, we assume that they can vary between 0 and 1; 0 implies the stock is 'empty' (e.g., no technological knowledge developed); while 1 means the development ceiling has been reached (e.g., a 'complete' understanding of the technology). Flows, depicted in Figure 2 for selected stocks, are depicted as pipes with valves and are responsible for changes (e.g., decrease or increase of the technological knowledge) in the stocks. Variables are those constructs that are dependent on stocks, flows, and/or other variables (e.g., the 'Total available resources'). The clouds (connected to the flows) represent processes that are beyond the scope of the model. For instance, for 'TIS structures' to grow, many 'microprocesses related to the various functions' are needed (e.g., actors meeting in conference to diffuse knowledge; decision making processes to invest in new infrastructure, etc.). In the current model, the exact relations between the functions and the TIS structures are black- 
boxed (which mirrors the approach developed by Hekkert et al., 2007) and are, as such, captured by a 'cloud'. Finally, in Figure 2, the loops are numbered: here a 'B' denotes a socalled balancing loop while a ' $R$ ' denotes a reinforcing loop.

\subsection{Model description}

The model recognizes the existence of the four motors (Suurs and Hekkert, 2012), which are subsequently translated into five feedback loops. These five loops consist of the seven functions as described by Hekkert et al. (2007). More specifically, the left side of Figure 2 constitutes technology development and is comprised of two balancing feedback loops: the 'Technology development loop' (loop B.1) and the 'Knowledge diffusion loop' (loop B.2). Together, they form the 'science and technology push' motor. The right side of the model mainly concerns market development, which is composed of three selfreinforcing feedback loops: the 'Entrepreneurial motor' (loop R.3), the 'System building motor' (loop R.4), and the 'Market motor'. Following our interpretation of Geels and Schot (2007) we also recognize the existence of the 'Regime resistance toward TIS' (loop B.6, also on the right side of the model in fig. 2)-counteracting the self-reinforcing market-side dynamics of the model.

\subsubsection{Science and technology push motor: Loop B.1 \& B.2}

Concerning the technological development side of the model, 'Technological knowledge developed' (B.1) and 'Technological knowledge diffused' (B.2) change (with a given delay) as a result of external resources (such as government funding or private capital), or, once developed, from internal resources flowing from the niche market). Both stocks decline if resource flows decline significantly or halt. As such, without a steady flow of resources to technological development-resulting from the function 'Resource mobilization' (a combination of external and internal resources)-there will be no TIS development. $^{7}$

\footnotetext{
${ }^{7}$ Note that the stock 'Technological knowledge diffused' represents the knowledge diffusion level
} belonging to the current level of 'Technological knowledge developed'. This implies that any positive change in the 'Technological knowledge developed' impacts the 'Technological knowledge diffused' in a negative manner (i.e., new knowledge has been developed requiring further diffusion activities). More specifically, any 
'Technological knowledge developed' and 'Technological knowledge diffused' shape the 'guidance of the search'. For example, the successful realisation of a research project, contributing to 'Technological knowledge developed' and/or to 'Technological knowledge diffused' can result in high expectations which contributes to the function 'Guidance of the Search' (Suurs and Hekkert, 2012). However, we note that, "guidance of the search is [...] often an interactive and cumulative process of exchanging ideas between technology producers, technology users, and many other actors, in which the technology itself is not a constant but a variable" Hekkert et al., (2007: 423). In empirical case studies, the 'Guidance of the Search' is often a function of government interventions such as innovation programs. Hence, in our model, these considerations are captured by the fact that 'Guidance of the Search' is shaped not only by technology development and diffusion, but also directly by the resources provided externally (e.g., from public innovation programs) and internally (e.g., resources flowing from niche markets).

\subsubsection{Entrepreneurial motor: Loop R.3}

The functions 'Perceived legitimacy of the TIS' and 'Entrepreneurial activity' play a key role in the 'Entrepreneurial motor loop' (R.3). The 'Perceived legitimacy of the TIS' is dependent on both technological legitimacy and market legitimacy. Technological legitimacy increases when technological knowledge development and diffusion increase. Market legitimacy increases when the TIS increasingly institutionalises in TIS structures (such as development of formal market rules, establishment of intermediary networks, the build up of infrastructure, or the development of formal regulations). Market legitimacy is also influenced negatively by regime resistance (e.g. when regime actors try to influence public discourses, or lobby against favourable support for a TIS).

Concerning the 'Entrepreneurial motor loop' (loop R.3), we note that a higher level of TIS legitimacy implies that entrepreneurs are more willing to undertake action in the TIS (not the least because the TIS is perceived to be in accordance with relevant regulations and institutions). This results in higher levels of 'Entrepreneurial activity'. We assume a curve- 
linear relationship, as depicted in Figure 3, between change in the 'Perceived legitimacy of the TIS' and change in 'Entrepreneurial activity'. Figure 3 implies that the higher the 'Perceived legitimacy of the TIS', the more entrepreneurs become active-simply because the risk associated with developing such propositions declines as the legitimacy increases; and vice versa. This relation then follows a 'band-wagon effect' (Geels, 2005; Suurs, 2009), where the rate of change in entrepreneurial activity increases, with a delay, the more entrepreneurial activity is installed. Subsequently, higher levels of 'Entrepreneurial activity' contribute positively to the 'Total available resources' in the TIS (Suurs, 2009).

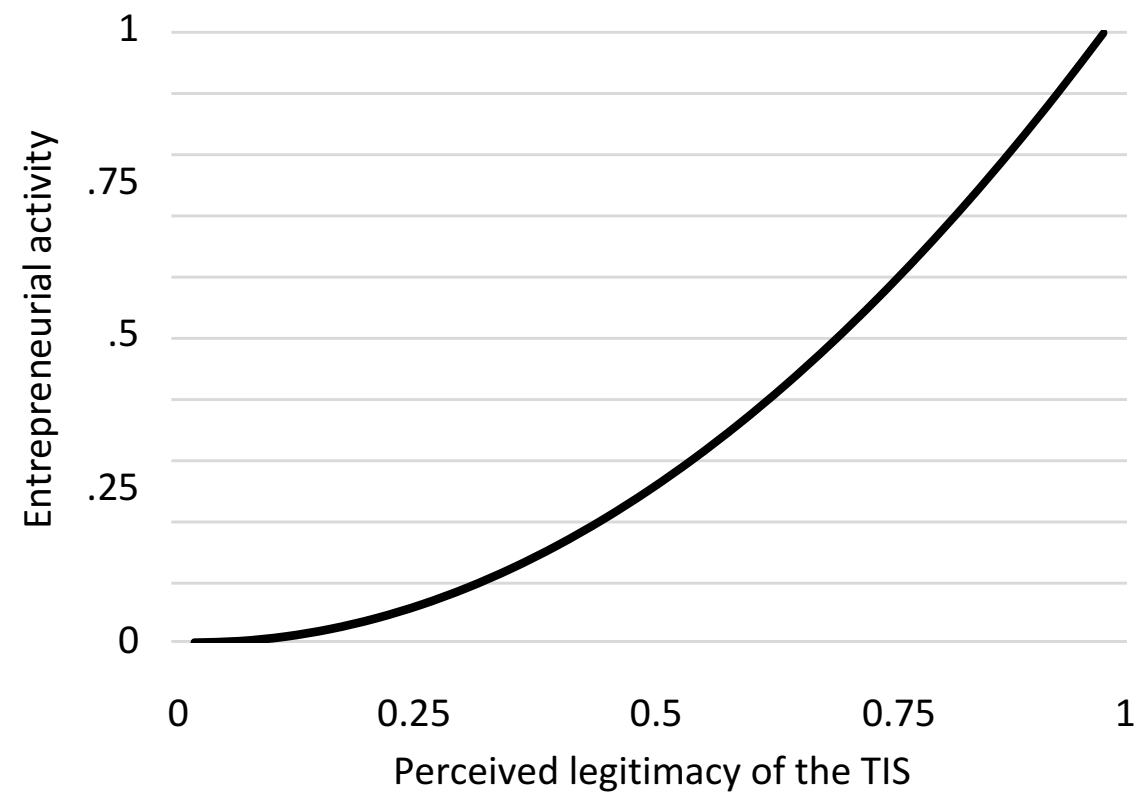

Figure 3. Non-linear relation between 'Perceived legitimacy of the TIS' and 'Entrepreneurial activity'.

\subsubsection{System building motor: Loop R.4}

An increase in 'Entrepreneurial activity' drives the 'System building motor loop' (loop R.4). More specifically, such growth implies development of actor networks (e.g., entrepreneurs organize themselves by broadening networks and setup intermediaries such as industry platforms, user intermediaries and other interest groups), infrastructural advances and attempts at institutional reconfigurations. The model captures this through the stock/flow of 'TIS structures'. We assume that the influence of entrepreneurs (and other actors for that matter) on the formation processes of 'TIS structures' becomes increasingly 
large as 'Entrepreneurial activity' increases - reflecting the need for a certain critical mass before substantial influence can be exercised. As such, we once more assume a delayed and non-linear relationship, as depicted in Figure 4 between 'Entrepreneurial activity' and 'TIS structures'. The emergence of 'TIS structures' provides face validity for the emerging TIS as it implies a widening range of actors to support the innovation system, resulting in broader societal support (Bergek et al., 2008a; Suurs, 2009). As such, growth in 'TIS structures' increases the 'Perceived legitimacy of the TIS', which makes the 'System building motor loop' reinforcing in nature.

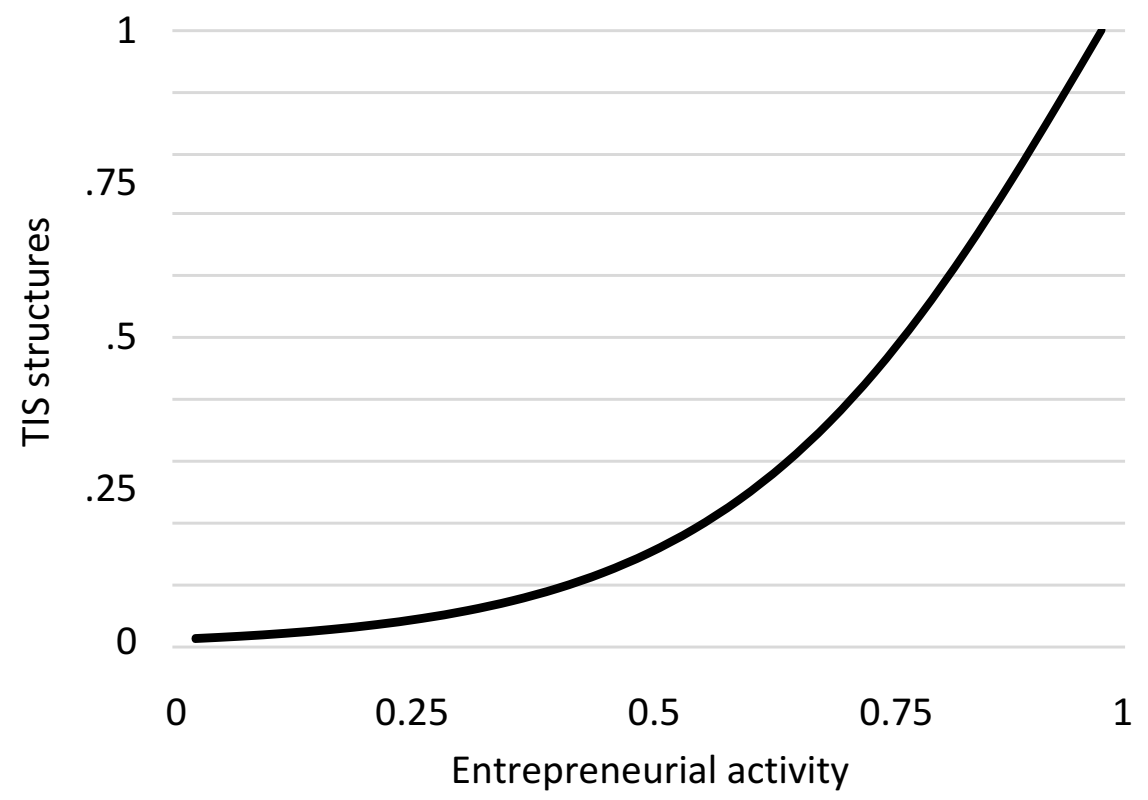

Figure 4. Non-linear relation between 'Entrepreneurial activity' and 'TIS structures'.

\subsubsection{Market motor: Loop R.5}

Growth in 'Entrepreneurial activity' also results, with a delay, in 'Niche market' growth (the 'Market motor loop', R.5). Yet, the 'Niche market' can only truly develop when innovation system actors successfully navigate the creation of 'TIS structures'. Over time an innovation system can become self-sufficient for maintaining all necessary processes in its system, because the niche market is able to generate the 'Total available resources' required to do so. In this respect, although all motors (loops) play an important role in the build-up of a TIS (Suurs and Hekkert, 2012), the 'Market motor loop' constitutes the most powerful self-reinforcing loop, potentially able to drive the whole system. 
We finally note that, as was the case for the technology development side of the model, all functions (stocks) in the entrepreneurial, system building and market motor decline if resource flows decline considerably or halt.

\subsubsection{The regime resistance loop: Loop B.6}

The final loop in the model is the 'Regime resistance loop' (B.6). This loop is added to the existing TIS framework to account for the potential feedback loops between a TIS and its context. The following relations are important in this loop. First, the growth of a TIS 'Niche market' triggers the 'Sailing ship effect', which implies that regime actors step up their efforts and increase 'Regime resistance toward TIS'. 'Regime resistance toward TIS' refers to work and actions by incumbent actors against the emergence of a TIS. Empirically, this may refer to, for instance, counter-lobbying and-framing, or resisting institutional changes (e.g., German utilities working against the feed-in tariff for renewables; see Jacobsson and Lauber, 2006). An underlying mechanism for this increase in resistance is, for instance, that regime actors fear competitive threats by the emerging TIS (e.g., threatening their existing business models), which leads them to increase their efforts to improve the performance of the existing regime through innovation. Regime resistance can also build up because components of the emerging TIS might 'spill over' to the existing regime (sailing ship effect), allowing for a (quickly achievable) performance increase of the regime. In our model, the regime resistance is stronger when in case of 'transformation' and 'technological substitution' pathways compared to 'de-alignment and re-alignment' and reconfiguration' pathways.

Second, the successful development of 'TIS structures' has a positive effect on the reduction of regime resistance. Here, the underlying mechanism is that the functional dynamics in a TIS shape the build up of TIS structures ${ }^{8}$, such as the establishment of

${ }^{8}$ In our model the exact relations between functions and structures are black-boxed in the stock/flow of 'TIS structures' (the black box is represented by a cloud), but the model does include a relation between resources availability and TIS structures (which reflects the possibility of internal and external resources to be used, for instance, for building infrastructures or facilitating networks). This follows the argument by Bergek et al. (2008a: 577): “When a radically new technology emerges, few of these structural components are in place. 
intermediary organisations, or investments in infrastructures, which in turn enables a TIS to become less dependent on external dynamics and counter-balance regime-resistance (Hillman and Sandén, 2008).

Finally, the 'Regime resistance loop' is influenced by landscape pressures following the transition pathway typology by Geels and Schot (2007). In case of a landscape pressure, the 'Regime resistance toward TIS' is temporarily reduced. ${ }^{9}$ In general, we assume in the current version of the model that the impact of 'Landscape pressure' on regime resistance remains present for 60 months and decreases regime resistance by 15 percentage points. ${ }^{10}$

The combination of the sailing ship effect, the dynamics in TIS structure and landscape pressure together shape the regime-resistance toward TIS, which can subsequently limit the 'Perceived legitimacy of the TIS' (and therefore dampen the growth of a 'Niche market'). Note that the 'Regime resistance toward TIS' is modelled as stock and flow, as change in the level of resistance is subject to complex delays and relationships which are beyond the scope of our model. We also assume that the incumbent regime 'reacts', but that it cannot do so forever as it will eventually reach its limit performance (De Liso \& Filatrella, 2008)-a ceiling to which the emerging TIS is assumingly not bound within the boundaries of the model. As such, the sailing ship effect and associated regime resistance is temporal: while its effect grows as the niche market develops, it can only sustain its negative influence on TIS growth for a given amount of time, after which its implications start to decline again.

The TIS must, thus, go through a formative phase, in which the constituent elements evolve and agglomerate through entry of firms and other organisations, formation of networks, institutional alignment and the accumulation of knowledge and physical artefacts."

${ }^{9}$ We note that landscape pressures can also strengthen regime resistance toward the TIS, for instance, globally decreasing oil prices may strengthen fossil fuel regimes and increase competition with TIS technologies in markets. Such regime re-enforcing landscape pressures can (easily) be modelled with the current model, but are currently not taken into account.

${ }^{10}$ Note that this methodological decision can be subject to further scrutiny in future versions of the model, for instance to investigate how qualitatively and quantitatively different kinds of landscape pressure influence TIS emergence (Geels and Schot, 2007). 


\subsection{Experimental setup}

To explore the working of the model and investigate how a TIS emerges (or declines) in the context of various transition pathways, we developed an experimental setup of three variable conditions: 1 ) the timing of the landscape pressure, 2 ) the type of relation between TIS and regime; and 3) the resource conditions.

The first variable condition is the timing of 'Landscape pressure' in relation to TIS development. In the experimental setup, the timing of the landscape pressure occurs either at a moment when the TIS has already started developing through the provision of external resources, or at a moment when the TIS has not yet started developing. In the latter case, external resources are provided at the same moment as the landscape pressure. ${ }^{11}$ This reflects the first criteria in the typology of transition pathways developed in Geels and Schot (2007).

The second variable condition relates to the relation between the TIS and the regime, which refers to the second criteria developed by Geels and Schot (2007). We consider two different sailing-ship effects, depending on the TIS-regime relationship: one where the incumbent regime is competitive with the TIS and one where it is symbiotic. These sailingship effects differ in terms of effect size (larger for the former) and effect duration (longer for the former). More specifically, we assume that a competitive regime is able to generate a sailing ship effect that increases the 'Regime resistance toward TIS' with up to 25

${ }^{11}$ These external resources feed into the 'Total available resources' (see Figure 2) and are subsequently divided over technology-development and market development. As described, all loops require continues flows of resources to function. This implies that a self-sustaining TIS is characterized by its ability to provide sufficient resources to maintain both technology and market development. Furthermore, the model has been programmed to distribute the available resources over the different loops in a fixed manner. More specifically, this concerns the distribution of resources that follow from 'Resource mobilization' over technology development and knowledge diffusion (i.e., constituting the technology development side of the model); and the distribution of resources that follow from 'Resources to market development' over 'Change in entrepreneurial activity' and 'Change in formal institutions and systems' (i.e., the market development side of the model), which distribution is also fixed. This has been done in an attempt to keep the model parsimonious and experimentation results interpretable. We refer to the Model Appendix for further details. 
percentage points for a period of 180 months; while a symbiotic regime induces a sailing ship effect of 5 percentage points for a period of 12 months.

The third variable condition relates to the 'resource conditions'. Resource conditions refers to the availability of external resources (such as finance or human capital) that a TIS can draw on. In general, we assume a fixed amount of resources, which does not change between model runs. However, in the current experimental setup we distinguish between three kinds of resource conditions. 'Technology-oriented conditions' refers to a situation where there is substantial resource availability for technological development (e.g., in the form of public and private R\&D support, or a large engineering labour market), but less resource availability for market development (e.g., subsidies to buy sustainable products). 'Market-oriented conditions' refer to the opposite situation. Significant resources are available for market development, but less so for technological development. Finally, 'hybrid conditions' refers to a situation where a TIS can initially draw substantially on technology-oriented resources, while in later development phases can draw on significant market-oriented resources. Table 1 provides an overview of the resource distribution between technology- and market-oriented conditions for each of these resource conditions. $^{12}$

Table 1. Resource conditions.

\begin{tabular}{|l|l|l|}
\hline Resource conditions & $\begin{array}{l}\text { Resources for technology } \\
\text { development }\end{array}$ & $\begin{array}{l}\text { Resources for market } \\
\text { development }\end{array}$ \\
\hline Technology-oriented conditions & $75 \%$ & $25 \%$ \\
\hline Market-oriented conditions & $25 \%$ & $75 \%$ \\
\hline Hybrid conditions & From $90 \%$ to $10 \%$ (in 36 months) & From $10 \%$ to $90 \%$ (in 36 months) \\
\hline
\end{tabular}

\footnotetext{
${ }^{12}$ These resource conditions allow us to experiment (albeit crudely) with various resource conditions.
} Nevertheless, we acknowledge that this an abstract way of modelling which, and the ways in which, resources are made available to a TIS. This part of the model can be further developed, for instance, to explore and evaluate the ways in which systemic instruments shape the dynamics of innovation systems under different regime contexts (Wieczorek and Hekkert, 2012; Weber and Rohracher, 2012; Smith et al., 2005). 
Finally, we experiment with a fixed amount of external resources for both 10 and 15 years, in order to determine the influence of the extend at which resources become available to a TIS over a relatively shorter or longer time-period. These time periods are roughly based on an average estimation of the 'valley of death' - the time that is required between invention and innovation. As such, we are able to investigate four transition pathways multiplied by three kinds of resource conditions, totalling 12 experiments. Furthermore, every experiment is conducted twice: (a) with 15 years and (b) 10 years of external resource availability. In all experiments, we investigate if the system's dynamics cause for sustained survival or exponential decline of the TIS.

Table 2. Experiment setup.

\begin{tabular}{|l|l|l|l|l|}
\hline & $\begin{array}{l}\text { De-alignment and re- } \\
\text { alignment }\end{array}$ & Reconfiguration & Transformation & $\begin{array}{l}\text { Technological } \\
\text { substitution }\end{array}$ \\
\hline Regime-TIS relation & Symbiotic & Symbiotic & Competitive & Competitive \\
\hline $\begin{array}{l}\text { TIS developed } \\
\text { before landscape } \\
\text { event? }\end{array}$ & No & Yes & No & Yes \\
\hline $\begin{array}{l}\text { Technology-oriented } \\
\text { resource conditions }\end{array}$ & Experiment 1a & Experiment 4a & Experiment 7a & Experiment 10a \\
\hline $\begin{array}{l}\text { Market-oriented } \\
\text { resource conditions }\end{array}$ & Experiment 2a & Experiment 5a & Experiment 8a & Experiment 11a \\
\hline & Experiment 2b & Experiment 5b & Experiment 8b & Experiment 11b \\
\hline Hybrid conditions & Experiment 3a & Experiment 6a & Experiment 9a & Experiment 12a \\
\hline & Experiment 3b & Experiment 6b & Experiment 9b & Experiment 12b \\
\hline
\end{tabular}

\subsubsection{Random variations and calibration}

We included several sources of random variation (i.e., pink noise, which refers to "noise processes with persistence", Sterman, 2000: 917) to the model. This influence, randomly generated for every simulation run, can be positive, negative or neutral compared to the normal system's dynamics, and is introduced to several important flows. More specifically, growth and decline in 'Technological knowledge developed', 'Technological knowledge diffused', 'Entrepreneurial activity', 'TIS structures', and 'Niche market' are all subject to this influence. These random variations can be interpreted as intrinsic uncertainties about interventions in technological innovation systems. Entrepreneurs, users, 
knowledge institutes and others actors may or may not respond to interventions, and it are these dynamics that this random variation aims to account for. ${ }^{13}$

\section{Results and discussion of the experiment}

We ran Monte-Carlo experiments: 250 runs per experiment, implying 6.000 runs in total. Table 3 provides an overview of the results. The table denotes the average value of 'Niche market' (over all 250 runs), at the end of the simulation run ( $t=600$, the final time step). These results presented in the table can be interpreted as relative indications of success; and can, given the model structure, range from 0 (no niche market) till 1 (full niche market developed). For instance, experiment $6 \mathrm{~b}$ resulted in an average niche market size of .180 (at $t=600$ over 250 runs). On the contrary, the result of experiment $1 \mathrm{a}$, in Table 3, equals .000 , implying none of the runs eventually lead to a self-sustaining niche market.

${ }^{13}$ We refer the interested reader to the model documentation, which contains more information, among others, concerning model calibration and robustness (incl. sensitivity) of the experimental setup. The model was found to be robust to variations in assumptions. 
Table 3. Results in terms of average 'Niche market' size at $t=600$.

The darker the background colour of the cell, the higher the success rate of that particular experiment.

\begin{tabular}{|c|c|c|c|c|}
\hline & $\begin{array}{l}\text { De-alignment and } \\
\text { re-alignment }\end{array}$ & Reconfiguration & Transformation & $\begin{array}{l}\text { Technological } \\
\text { substitution }\end{array}$ \\
\hline Regime-TIS relation & Symbiotic & Symbiotic & Competitive & Competitive \\
\hline $\begin{array}{l}\text { TIS developed } \\
\text { before landscape } \\
\text { event? }\end{array}$ & No & Yes & No & Yes \\
\hline $\begin{array}{l}\text { Technology } \\
\text { development: 15y }\end{array}$ & $\begin{array}{l}\text { Experiment 1a: } \\
.000\end{array}$ & $\begin{array}{l}\text { Experiment 4a: } \\
.000\end{array}$ & $\begin{array}{l}\text { Experiment 7a: } \\
.000\end{array}$ & $\begin{array}{l}\text { Experiment 10a: } \\
.000\end{array}$ \\
\hline $\begin{array}{l}\text { Technology } \\
\text { development: 10y }\end{array}$ & $\begin{array}{l}\text { Experiment } 1 \mathrm{~b}: \\
.000\end{array}$ & $\begin{array}{l}\text { Experiment 4b: } \\
.000\end{array}$ & $\begin{array}{l}\text { Experiment 7b: } \\
.000\end{array}$ & $\begin{array}{l}\text { Experiment 10b: } \\
.000\end{array}$ \\
\hline $\begin{array}{l}\text { Market } \\
\text { development: 15y }\end{array}$ & $\begin{array}{l}\text { Experiment 2a: } \\
.000\end{array}$ & $\begin{array}{l}\text { Experiment 5a: } \\
.000\end{array}$ & $\begin{array}{l}\text { Experiment 8a: } \\
.000\end{array}$ & $\begin{array}{l}\text { Experiment 11a: } \\
.000\end{array}$ \\
\hline $\begin{array}{l}\text { Market } \\
\text { development: 10y }\end{array}$ & $\begin{array}{l}\text { Experiment } 2 \mathrm{~b}: \\
.001\end{array}$ & $\begin{array}{l}\text { Experiment } 5 b: \\
.008\end{array}$ & $\begin{array}{l}\text { Experiment 8b: } \\
.000\end{array}$ & $\begin{array}{l}\text { Experiment 11b: } \\
.000\end{array}$ \\
\hline $\begin{array}{l}\text { Hybrid } \\
\text { development: 15y }\end{array}$ & $\begin{array}{l}\text { Experiment 3a: } \\
.039\end{array}$ & $\begin{array}{l}\text { Experiment 6a: } \\
.048\end{array}$ & $\begin{array}{l}\text { Experiment 9a: } \\
.006\end{array}$ & $\begin{array}{l}\text { Experiment 12a: } \\
.009\end{array}$ \\
\hline $\begin{array}{l}\text { Hybrid } \\
\text { development: 10y }\end{array}$ & $\begin{array}{l}\text { Experiment 3b: } \\
.149\end{array}$ & $\begin{array}{l}\text { Experiment } 6 \mathrm{~b} \text { : } \\
.180\end{array}$ & $\begin{array}{l}\text { Experiment 9b: } \\
.022\end{array}$ & $\begin{array}{l}\text { Experiment } 12 \mathrm{~b}: \\
.037\end{array}$ \\
\hline Legend: & $<.001$ & $<=.001 x<.01$ & $<=.01 x<.10$ & $>=.10$ \\
\hline
\end{tabular}

Figures 5 and 6 show the results of the same experiments ( $6 \mathrm{~b}$ and $1 \mathrm{a}$ respectively) in a dynamic manner, illustrating niche market size of all 250 runs for both experiments over time. Each figure (as well as the other figures in this section) consists of 250 black lines (i.e., all individual runs per experiment). The red line denotes the average value of all individual runs, while the blue line illustrates the behaviour of a single (randomly chosen) run. Also, the mean and standard deviation (SD) of the results at $t=600$ are provided. 


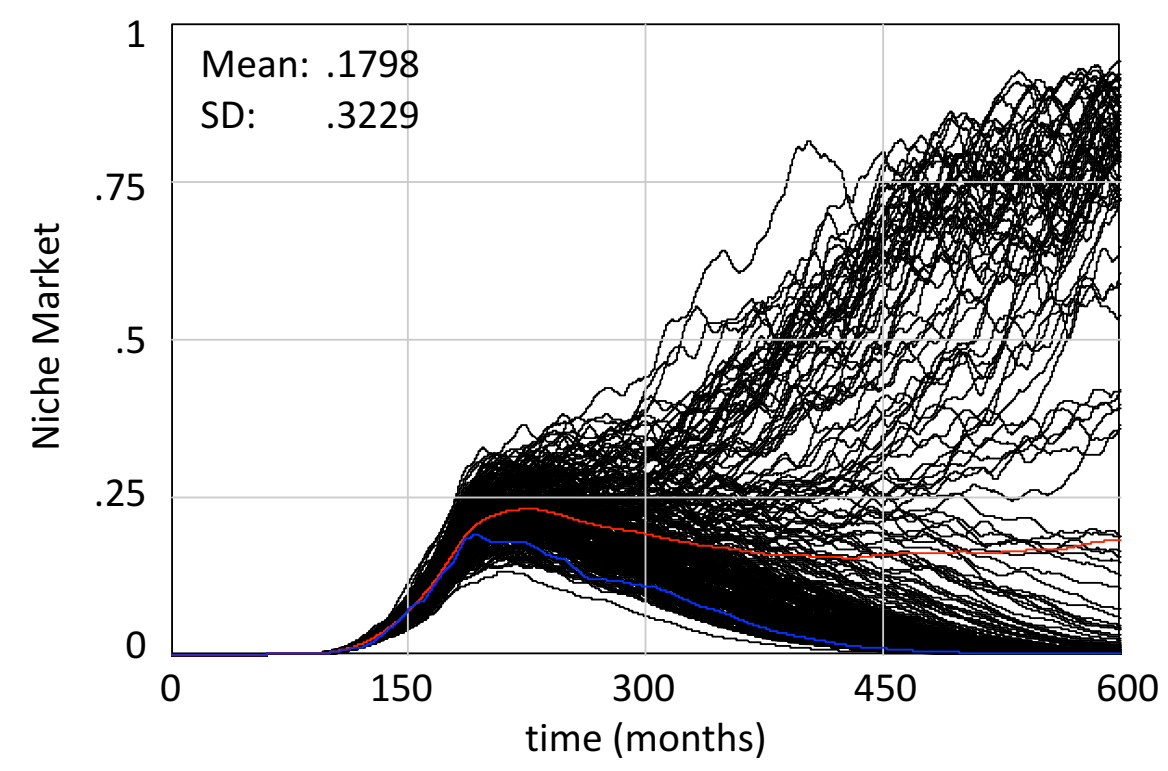

Figure 5. The results for 'Niche market', experiment $6 \mathrm{~b}$.

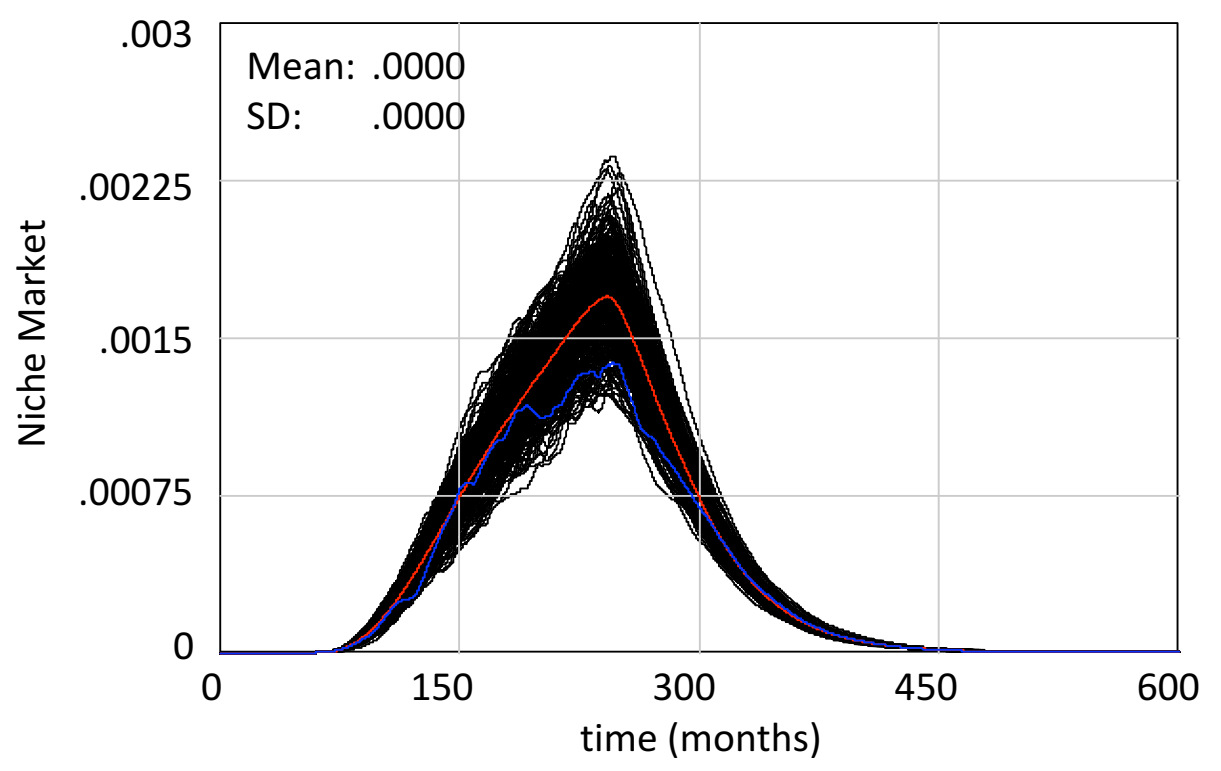

Figure 6. The results for 'Niche market', experiment 1a.

On the basis of Table 3 and the graphs in this section, we highlight the following results and discussion points. First, the table shows that in case of hybrid resource conditions (i.e., a combination of technology-oriented resource availability and marketoriented resource availability) the average niche market size is largest, independent of the transition pathway. Moreover, Table 3 shows that under technology-oriented resource conditions, (hardly) any niche markets are created in any transition pathway. These results are in line with earlier empirical findings suggesting that without resources for market 
development, markets for radical innovations are unlikely to emerge, especially in cases of eco-innovation (Garud and Karnoe, 2002; Costantini et al., 2015; Koseoglu et al., 2013).

Second, in a reconfiguration pathway the average niche market size is larger compared to other transition pathways, in particular under market-oriented or hybrid resource conditions. This is because in a reconfiguration pathway the regime context responds in symbiotic ways to the emerging TIS, limiting the sailing ship, and the TIS has already developed to some extent before a window of opportunity arose. Both create favourable circumstances for niche market development (Geels and Schot, 2007). However, even in the context of a reconfiguration pathway, poor resource conditions (in our case technology-oriented resource conditions) can still limit or even diminish the potential for niche market growth, as indicated with (close to) zero average niche market sizes in Table 3 and also figure 6 .

Third, shorter but more substantial resource availability (in our case 10 years instead of 15 years with the same amount of resources) is associated with higher average niche market sizes, independent of other resource conditions (technology development, market development or hybrid), or its context (four transition pathways). This has arguably to do with the relatively short window of opportunity of 60 months, modelled by means of the exogenous 'Landscape pressure'. As explained, the effect of 'Landscape pressure' is a reduction in the 'Regime resistance toward TIS'. Figure 7 (10-year resource availability) and 8 (15 year resource availability) illustrate how the interplay between the length of resource availability and landscape pressure influences TIS development. In these figures, the dotted vertical lines denote the window of opportunity of 60 months. In Figure 7, the 'Regime resistance toward TIS' is much lower when the window of opportunity closes after 60 months, compared to Figure 8, suggesting that the TIS is more likely to become selfsustaining (i.e., 'internally resourced'). 


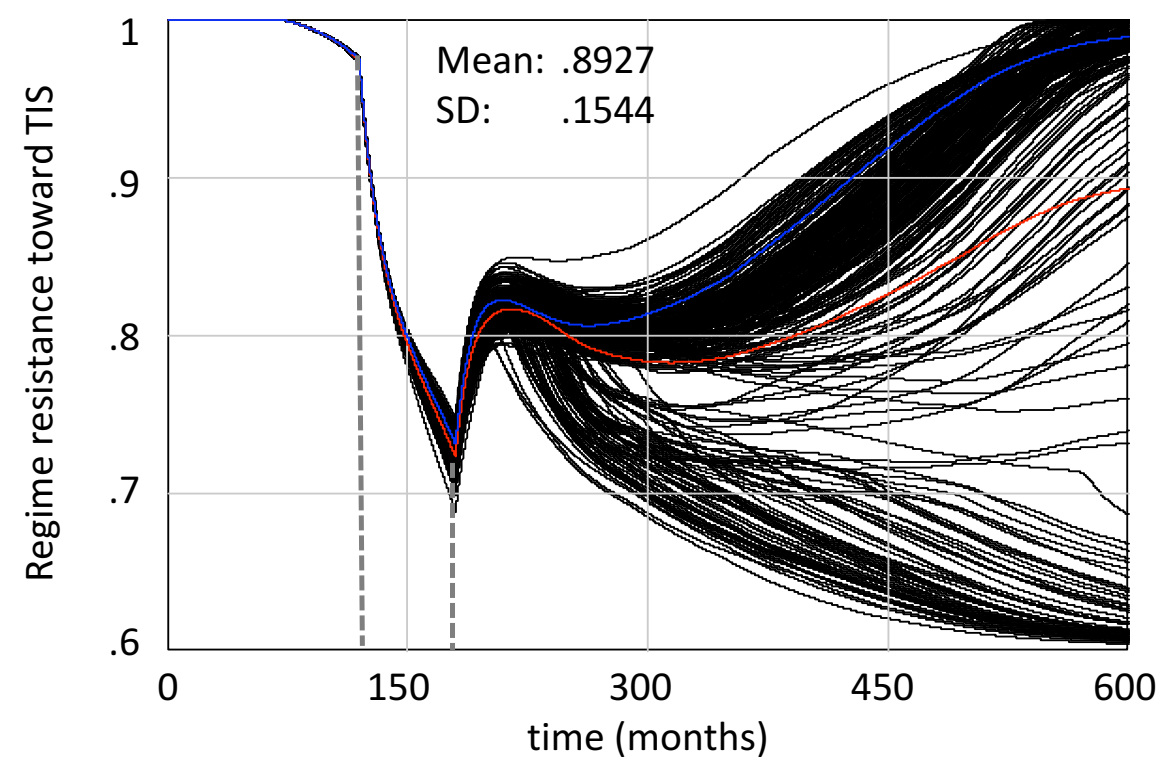

Figure 7. The results for 'Regime resistance toward TIS', experiment $6 \mathrm{~b}$ (10 years of resource availability).

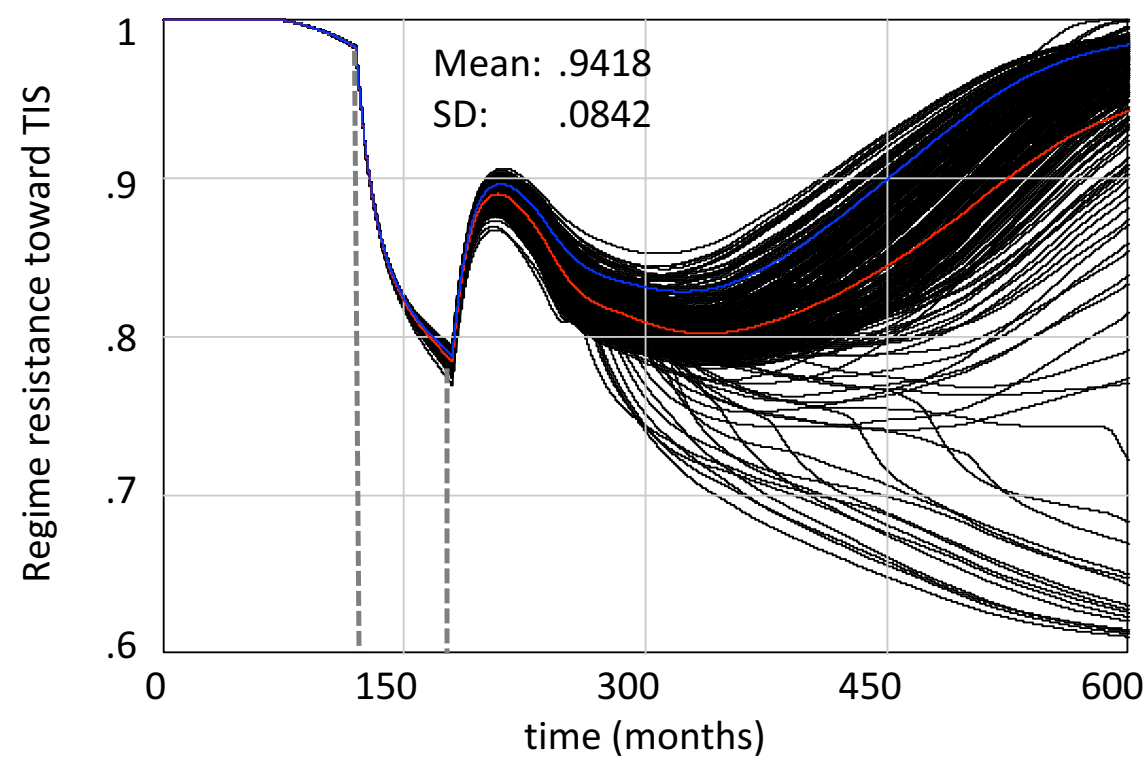

Figure 8. The results for 'Regime resistance toward TIS', experiment 6a (15 years of resource availability).

Fourth, as evidenced in Table 3, niche market sizes vary significantly between transition paths characterized by a symbiotic relationship versus those characterized by a competitive relationship (higher for the latter). In other words, these findings illustrate the potentially strong influence of the 'Sailing ship effect'. This effect can be clearly seen in the difference between Figures 9 and 10 (symbiotic and competitive respectively). The figures show the behaviour of the stock 'Regime resistance toward TIS' for two simulation runs, both under hybrid resource conditions of 10 years and with no TIS development before the 
landscape pressure occurs. As such, the experiments only differ in terms of their Regime-TIS relation. As can be seen in both figures, the level of resistance steadily declines from $t=60$, due to resource availability and the influence of the landscape pressure, which reduce regime resistance. From about $t=120$ onward, the sailing ship effect causes an increase in the regime resistance toward the TIS. This negative effect on the TIS is notably larger and longer in the case of 'competitive' Regime-TIS relations (Figure 10) compared to 'symbiotic' Regime-TIS relations (Figure 9). As a result, in the competitive case, only a few individual traces overcome the regime resistance, and only around $t=400$. The sailing ship effect in the symbiotic case is in many more cases overcome around $t=225$.

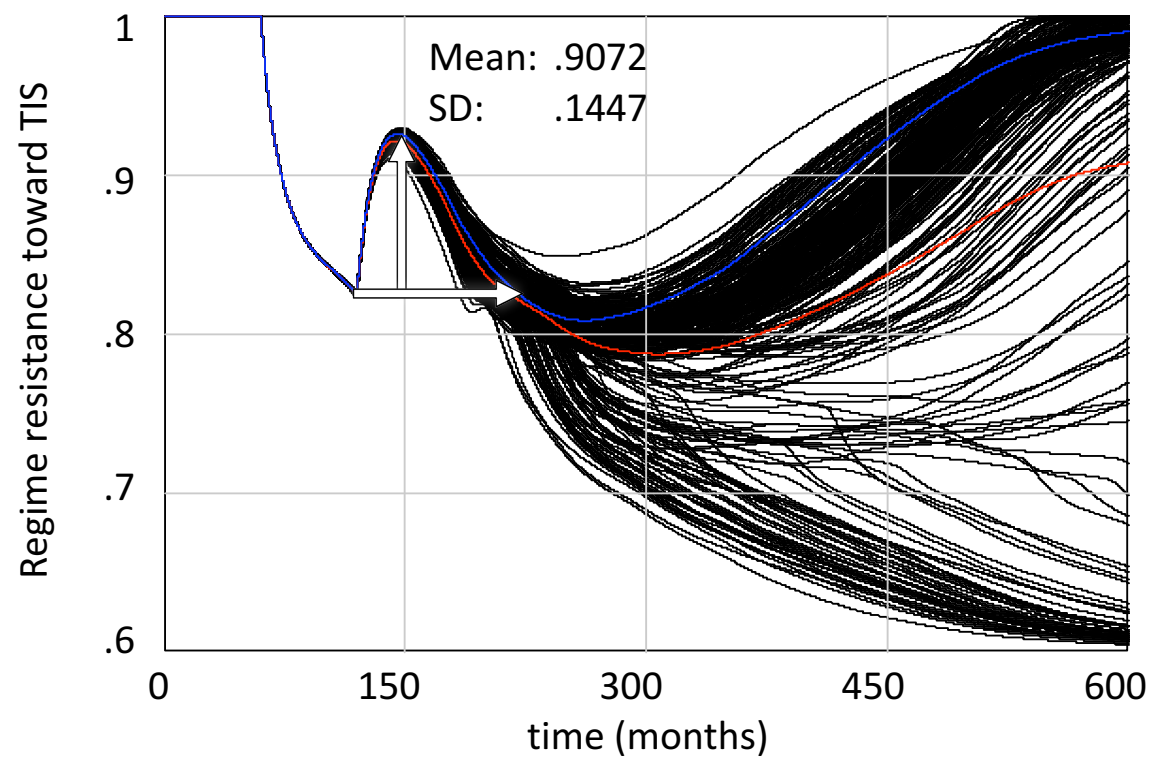

Figure 9. The results for 'Regime resistance toward TIS', experiment 3b (symbiotic relationship). 


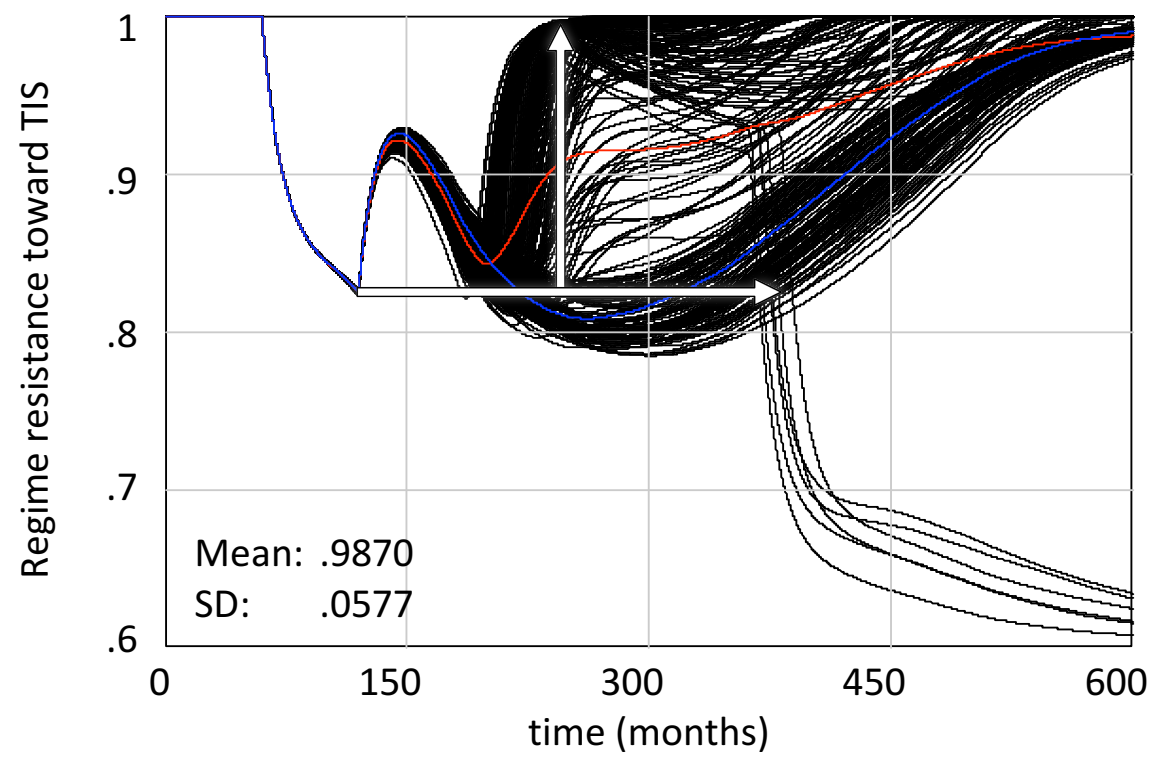

Figure 10. The results for 'Regime resistance toward TIS', experiment 9b (competitive relationship).

Fifth, the results demonstrate that those cases where a TIS has already developed before a landscape pressure occurs are associated with higher average niche market sizes, compared to cases where TIS support is only put in place at the moment of the landscape pressure. This is demonstrated by the larger average niche markets in the 'reconfiguration' and 'technological substitution' pathways compared to the 'de-alignment and re-alignment' and 'transformation' pathways respectively. This highlights the importance of the relative timing of landscape pressures, which may have important governance implications, including (improvement of) the capacity to anticipate future windows of opportunities (Nill and Kemp, 2009; Garud and Gehman, 2012). 


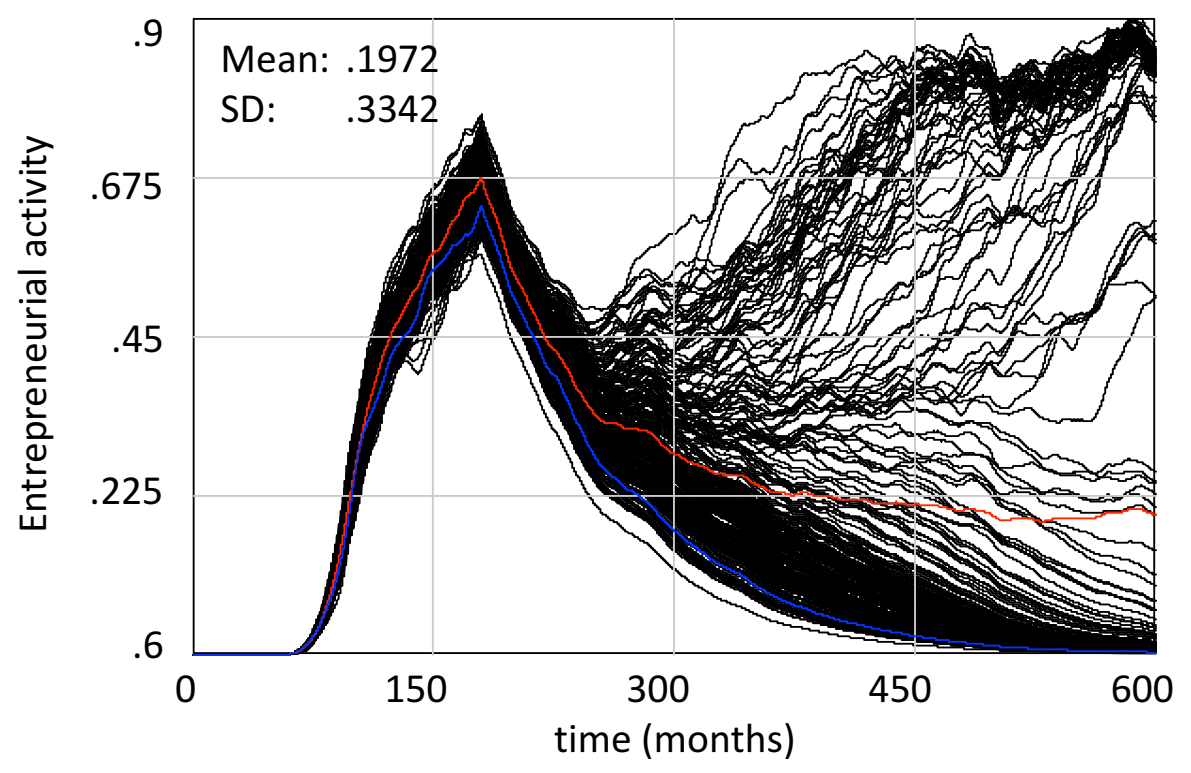

Figure 11. The results for 'Entrepreneurial activity', simulation run $6 \mathrm{~b}$.

Sixth, the model is able to capture non-linear dynamics and uncertainties associated with emerging niches or technological innovation systems (Geels and Raven, 2006; Meijer and Hekkert, 2007). This is, for instance, illustrated in Figure 11, which shows the result of 'Entrepreneurial activity' under hybrid resource conditions and in the context of a reconfiguration pathway (i.e., experiment $6 \mathrm{~b}$ ). The figure shows clearly the ups and downs in entrepreneurial activity, typical for emerging innovations (Negro et al., 2008). The figure also shows that even under hybrid resource conditions in the context of a reconfiguration pathway, there is no blueprint for success. In the model this is captured through random variations in important flows; in reality these uncertainties are constituted by a range of social processes and agencies through which actors respond in differentiated ways to resource conditions, for instance because of fundamentally different appraisal of the innovation system (Smith and Stirling, 2007).

Finally, Figure 11 also shows the existence of a so-called tipping point. That is, the sailing ship effect is either overcome and a self-sustaining niche market is created, or the sailing ship effect is not overcome which inevitably results in decline/failure of the TIS.

\section{Conclusions and outlook}

In this paper we set out to investigate how technological innovation systems emerge, or decline, in the context of various socio-technical transition pathways. We did so by developing a system dynamics model, which is grounded in both the 'motors of innovation', 
following the literature on emerging technological innovation systems (Suurs and Hekkert, 2012; Suurs, 2009) and the notion of 'transition pathways' as part of the multi-level framework thinking (Geels and Schot, 2007). As such, this paper contributes to the literature by making a cross-over between TIS and MLP, two key-frameworks (Markard and Truffer, 2008; Weber and Rohracher, 2012), into a system dynamics model serves as underpinning for future research.

In order to illustrate the dynamics that emerge from such cross-over, we developed several experiments characterized by exogenous influences. While the individual experiments and outcomes are described in detail in the previous section, our overall conclusion is that the model is able to produce results similar to what can be expected on the basis of existing TIS and MLP literature. As such, the results illustrate that we can have confidence in the overall functioning of the model, albeit only roughly. In this sense the development of a formal model follows a similar approach to the development of a conceptual model (such as TIS or MLP itself). Initial assumptions and ideas about relations between, for instance, niche-regime-landscape levels or TIS functions are combined into a framework, which can then serve to analyse empirical cases, which help to further refine the framework. In this respect, the developed formal model provides an important first step into the direction of more formalised models of TIS, which allows for future research in various manners, which, in turn, allows further fine-tuning of the formal model.

A key feature of the model is the explicit inclusion of context (i.e., captured by MLP), which has been recently theorized by Bergek et al. (2015) to be a critical element of future TIS development. More specifically, our take on context is captured by the 'Regime resistance toward TIS'. This effect provides an important balancing feedback loop against the self-reinforcing TIS functions, and represents path-dependency and resistance emerging from incumbent socio-technical systems. As such, the contextual feedback is essential, as without this strong balancing force, the reinforcing nature of the TIS would cause it to develop unrestricted (from start to finish).

Furthermore, the introduction of context through the balancing feedback loop introduces an important tipping point to the system which, we suggest, might have important implications. In general, the existence of a tipping point is important because, once crossed, the dynamics in the system change (Sterman, 2000). Here the tipping point refers to the moment at which the self-reinforcing nature of the TIS is no longer 
counteracted by the sailing ship effect. Indeed, if crossed, a self-sustaining niche market arises. Yet, if this point is not reached, the TIS will decline and disappear. The results of our experiments clearly demonstrate such either-or behaviour. While further research is needed to investigate the precise nature of this tipping point (we chose to model initial growth of a TIS and, therefore, are not certain about the dynamics in subsequent phases), it could have important consequences for the governance of TIS.

Various research directions, building on the presented work, can be explored. First, the current model is not calibrated to a specific innovation system, but builds on generic causal relationships identified in the literature, in the context of TIS emergence. Future work, informed by our model, could pursue calibration to specific cases, phases and spatial contexts-also in order to validate more specific relations in the model. For instance, can we reproduce the ways in which Dutch and German niche markets and innovation systems for solar photovoltaic electricity have developed in response to various, nationally different, public policies? Second, in future research the model might be adapted for the investigation and advancement of governance strategies, for instance, by further developing and experimenting with the resource conditions in different transition-pathways. In particular, it would be fruitful to use the model to explore the influence of different kinds of systemic instruments in different phases of TIS development (Wieczorek and Hekkert, 2012). Third, the model could be further developed to further unpack the relations between functions and structures in TIS, which is currently only modelled in at an aggregated level. Fourth, future research may use the model to zoom in more specifically on the role of consumers (or other actors for that matter) in transitions and distinguish between various kinds of consumers (or other actors). This direction can, for instance, be pursued by combining the presented model with an agent-based model (which would allow for modelling agency). Finally, future work can extend the model to include the interplay between multiple TIS emerging in the context of one or multiple regime(s). Arguably, the challenge for any modeller is to keep their work as parsimonious as possible, hence such an endeavour would probably imply the need to black-box some of the TIS-internal causal relationships as identified in the current model. These are, however, only some directions that can be explored by means of the presented work. 
We end the paper with a reflection on the use of formal modelling for analysis of the dynamics of TIS, and-more generally-analysis of socio-technical transitions. ${ }^{14} \mathrm{~A}$ simulation model can serve as means to specifying assumptions and theoretical logic that lie at the heart of verbal theories (see Davis et al., 2007). In this respect, simulation provides a way for further specifying and extending extant transition theory and methods. Nevertheless, modelling, like any method, has its limitations. In particular questions pertain to the extent at which formal modelling is suitable for complex and multi-dimensional problems such as a socio-technical transition. For instance, formal models are often critiqued for lacking realworld realism and accuracy; simulation research may be based on unrealistic assumptions; and simulation constructs are often allowed to vary only between empirically distant values (such as 0 and 1) (Davis et al., 2007). Some argue that the limitations of models are such that they are inherently incapable of dealing with wicked problems, referring to both complicatedness and complexity of socio-technical systems, and that narrative theory is better equipped as a methodological approach for analysis of wicked problems (Andersson et al., 2014). Whilst we are sympathetic to these considerations, we note that this paper built upon a conceptual model that is strongly informed by narrative case studies, and that the model only covers the first phase of a transition. In general, a multi-method approach including both formal modelling and narrative case studies (and action research for that matter) may prove to be a promising combination. Indeed, Turnheim et al. (2015) have recently argued for a bridging approach between formal modelling, socio-technical analysis and practice-based learning (rather than an integrative approach). In this perspective, we consider our model, and its options for future research, primarily as addition to the current methods found in the field of innovation system and transition studies. In other words, the ambition of the current paper was to develop a formal model on the basis of an existing conceptual, narrative framework, and as such, expand the methodological toolbox of transition studies. We hope that our work inspires future research so that together we may push the boundaries of transition studies further.

\footnotetext{
${ }^{14}$ We thank one of the reviewers for point us in the direction of this reflection. For ontological
} reflections on frameworks in transition studies we also refer to e.g., Geels (2010). 


\section{Acknowledgements}

We would like to thank three reviewers, Anna Bergek and Björn Sandén for their comments on previous versions of this paper. We are also grateful to the members of the Innovation Studies group in Utrecht for providing us with feedback during a presentation of this work, as well as participants of the International Sustainability Transitions 2015 Conference. This research did not receive any specific grant from funding agencies in the public, commercial, or not-for-profit sectors.

\section{References}

Adner, R., Snow, D., 2010. Old technology responses to new technology threats: demand heterogeneity and technology retreats. Ind. Corp. Change. 19, 1655-1675.

Andersson, C., Törnberg, A., Törnberg, P. 2014. Societal systems-Complex or worse? Futures. 63, 145-157.

Bergek, A., Jacobsson, S., Carlsson, B., Lindmark, S., Rickne, A., 2008a. Analyzing the functional dynamics of technological innovation systems: A scheme of analysis. Res. Policy. 37, 407-429.

Bergek, A., Jacobsson, S., Sandén, B.A., 2008b. "Legitimation" and "development of positive externalities": Two key processes in the formation phase of technological innovation systems. Technol. Anal. Strateg. Manag. 20, 575-592.

Bergek, A., Hekkert, M., Jacobsson, S., Markard, J., Sandén, B., Truffer, B. 2015. Technological innovation systems in contexts: Conceptualizing contextual structures and interaction dynamics. Environ. Innov. Soc. Transit. 16, 51-64.

Bergman, N., Haxeltine, A., Whitmarsh, L., Köhler, J., Schilperoord, M., Rotmans, J., 2008. Modelling socio-technical transition patterns and pathways. J. Artif. Soc. Soc. Simul. $11,7$.

Club of Rome, 1972. The Limits to growth: A report for the Club of Rome's project on the predicament of mankind. Universe Books, New York.

Cooper, A.C., Smith, C.G., 1992. How established firms respond to threatening technologies. Acad. Manage. Exec. 6, 55-70. 
Costantini, V., Crespi, F., Martini, C., Pennacchio, L., 2015. Demand-pull and technologypush public support for eco-innovation: the case of the biofuels sector. Res. Policy. 44, 577-595.

Davis, J.P., Eisenhardt, K.M., Bingham, C.B., 2007. Developing theory through simulation methods. Acad. Management Rev. 32, 480-499.

De Liso, N., Filatrella, G., 2008. On technology competition: A formal analysis of the "sailingship effect." Economics of Innovation and New Technology. 17, 593-610.

Garud, R., Gehman, J., 2012. Metatheoratical perspectives on sustainability journeys: Evolutionary, relational and durational. Res. Policy. 41, 980-995.

Garud, R., Karnoe, P., 2002. Bricolage versus breakthrough. Distributed and embedded agency in technology entrepreneurship. Res. Policy. 32, 277-300.

Geels, F.W., 2005. Processes and patterns in transitions and system innovations: Refining the co-evolutionary multi-level perspective. Technol. Forecast. Soc. Change. 72, 681696.

Geels, F.W., 2002. Technological transitions as evolutionary reconfiguration processes: a multi-level perspective and a case-study. Res. Policy. 31, 1257-1274.

Geels, F. W., Raven, R. P. J. M., 2006. Non-linearity and expectations in niche-development trajectories: Ups and downs in Dutch biogas development (1973-2003). Technol. Anal. Strateg. 18, 375-392.

Geels, F.W., Schot, J., 2007. Typology of sociotechnical transition pathways. Res. Policy. 36, 399-417.

Geels, F.W., 2010. Ontologies, socio-technical transitions (to sustainability), and the multilevel perspective. Res. Policy. 39, 495-510.

Geels, F.W., 2014. Regime resistance against low-carbon energy transitions: Introducing politics and power in the multi-level perspective. Theor. Cult. Soc. 31(5), 21-40.

Halbe, J., Reusser, D.E., Holtz, G., Haasnoot, M., Stosius, A., Avenhaus, W., Kwakkel, J.H., 2015. Lessons for model use in transition research: A survey and comparison with other research areas. Environ. Innov. Soc. Transit. 15, 194-210.

Hekkert, M.P., Suurs, R.A.A., Negro, S.O., Kuhlmann, S., Smits, R.E.H.M., 2007. Functions of innovation systems: A new approach for analysing technological change. Technol. Forecast. Soc. Change. 74, 413-432. 
Hillman, K.M., Sandén, B., 2008. Exploring technology paths: The development of alternative transport fuels in Sweden 2007-2020. Technol. Forecast. Soc. Change. 75, 12791302.

Holtz, G., Alkemade, F., Haan, F., Köhler, J., Trutnevyte, E., Luthe, T., Halbe, J., Papachristos, G., Chappin, E., Kwakkel, J., Ruutu, S., 2015. Prospects of modelling societal transitions: Position paper of an emerging community. Environ. Innov. Soc. Transit. $17,41-58$.

Holtz, G., 2011. Modelling transitions: An appraisal of experiences and suggestions for research. Environ. Innov. Soc. Transit. 1, 167-186.

Howell, J., 2002. The response of old technology incumbents to technological competition does the sailing ship effect exist? Journal of Technology Management. 39, 887-906. Jacobsson, S., Bergek, A., 2004. Transforming the energy sector: the evolution of technological systems in renewable energy technology. Ind. Corp. Change. 13, 815849.

Jacobsson, S., Lauber, V., 2006. The politics and policy of energy system transformationexplaining the German diffusion of renewable energy technology. Energ. Policy. 34, 256-276.

Kemp, R., Schot, J., Hoogma, R., 1998. Regime shifts to sustainability through processes of niche formation: The approach of strategic niche management. Technol. Anal. Strateg. Manag. 10, 175-198.

Koseoglu, N.M., Bergh, J.C.J.M. van den, Subtil Lacerda, J., 2013. Allocating subsidies to R\&D or to market applications of renewable energy? Balance and geographical relevance. Energy for Sustainable Development. 17, 536-545.

Köhler, J., Whitmarsh, L., Nykvist, B., Schilperoord, M., Bergman, N., Haxeltine, A., 2009. A transitions model for sustainable mobility. Ecol. Econ. 68, 2985-2995.

Loorbach, D., 2010. Transition management for sustainable development: a prescriptive, complexity-based governance framework. Governance. 23, 161-183.

Lopolito, A., Morone, P., Taylor, R., 2013. Emerging innovation niches: An agent based model. Res. Policy. 42, 1225-1238.

Markard, J., Raven, R., Truffer, B., 2012. Sustainability transitions: An emerging field of research and its prospects. Res. Policy. 41, 955-967. 
Markard, J., Truffer, B., 2008. Technological innovation systems and the multi-level perspective: Towards an integrated framework. Res. Policy. 37, 596-615.

Meijer, I., Hekkert, M. P. 2007. Managing uncertainties in the transition towards sustainability: Cases of emerging energy technologies in the Netherlands. Journal of Environmental Policy \& Planning, 9, 281-298.

Negro, S.O., Suurs, R.A.A., Hekkert, M.P., 2008. The bumpy road of biomass gasification in the Netherlands: Explaining the rise and fall of an emerging innovation system. Technol. Forecast. Soc. Change. 75, 57-77.

Nill, J., Kemp, R., 2009. Evolutionary approaches for sustainable innovation policies: From niche to paradigm? Res. Policy. 38, 668-680.

Raven, R.P.J.M., 2006. Towards alternative trajectories? Reconfigurations in the Dutch electricity regime. Res. Policy. 35, 581-595.

Raven, R.P.J.M., Kern, F., Verhees, B., Smith, A., 2016. Niche construction and empowerment through socio-political work. A meta-analysis of six low-carbon technology cases. Environ. Innov. Soc. Transit. 18, 164-180.

Rip, A., Kemp, R., 1998. Technological Change, in: Rayner, S., Malone, E.L. (Eds.), Human Choice and Climate Change: An International Assessment. Battelle Press, Columbus, pp. 327-401.

Rotmans, J., Jäger, J., Weaver, P., 2008. Editorial for the special issue on MATISSE. Int. J. Innov. Sustain. Dev. 3, 1-8.

Rotmans, J., Kemp, R., Van Asselt, M., 2001. More evolution than revolution: Transition management in public policy. Foresight. 3, 15-31.

Safarzyńska, K., Frenken, K., van den Bergh, J.C.J.M., 2012. Evolutionary theorizing and modeling of sustainability transitions. Res. Policy. 41, 1011-1024.

Schot, J., Geels, F.W., 2008. Strategic niche management and sustainable innovation journeys: Theory, findings, research agenda, and policy. Technol. Anal. Strateg. Manag. 20, 537-554.

Schot, J., Geels, F.W., 2007. Niches in evolutionary theories of technical change: A critical survey of the literature. J. Evol. Econ. 17, 605-622.

Smink, M.M., Hekkert, M.P. and Negro, S.O., 2013, Keeping sustainable innovation on a leash? Exploring incumbents' institutional strategies. Business Strategy and the Environment. 24(2), 86-101. 
Smith, A., Raven, R., 2012. What is protective space? Reconsidering niches in transitions to sustainability. Res. Policy. 41, 1025-1036.

Smith, A., Stirling, A., Berkhout, F., 2005. The governance of sustainable socio-technical transitions. Res. Policy. 34, 1491-1510.

Smith, A., Stirling, A., 2007. Moving outside or inside? Objectification and reflexivity in the governance of socio-technical systems. Journal of Environmental Policy \& Planning. 9, 3-4, 351-373.

Sterman, J.D., 2000. Business Dynamics: Systems Thinking and Modeling for a Complex World, McGraw Hill, New York.

Suarez, F.F., Oliva, R., 2005. Environmental change and organisational transformation. Ind. Corp. Change. 14(6), 1017-1041.

Suurs, R.A.A., 2009. Motors of Sustainable Innovation: Toward a theory on the dynamics of technological innovation systems. Utrecht University, Utrecht.

Suurs, R.A.A., Hekkert, M.P., Smiths, R.E.H.M., 2009. Understanding the build-up of a technological innovation system around hydrogen and fuel cell technologies. Int. J. Hydrogen. Energ. 34, 9639-9654.

Suurs, R.A.A., Hekkert, M.P., Kiekeboom, S., Smits, R.E.H.M., 2010. Understanding the formative stage of technological innovation system development: the case of natural gas as an automative fuel. Energ. Policy. 38, 419-431.

Suurs, R., Hekkert, M., 2012. Motors of sustainable innovation. Understanding transitions from a technological innovation system's perspective, in: Verbong, G., Loorbach, D. (Eds.), Governing the Energy Transition. Reality, Illusion or Necessity? Routledge, pp. 152-179.

Turnheim, B., Berkhout, F., Geels, F.W., Hof, A., McMeekin, A., Nykvist, B., Vuuren, D.P. van, 2015. Evaluating sustainability transitions pathways: bridging analytical approaches to address governance challenges. Global Environ. Chang. 35, 239-253.

Voss, J.P., Bauknecht, D., Kemp, R., 2006. Reflexive governance for sustainable development. Edward Elgar, Cheltenham, UK; Northampton, MA.

Walrave, B., Van Oorschot, K.E., Romme, A.G.L., 2011. Getting trapped in the suppression of exploration: A simulation model. J. Manage. Stud. 48, 1727-1751.

Walrave, B., van Oorschot, K.E., Romme, A.G.L., 2015. How to counteract the suppression of exploration in publicly traded corporations. R\&D Manage. 45, 458-473. 
Weber, K.M., Rohracher, H., 2012. Legitimizing research, technology and innovation policies for transformative change. Res. Policy 41, 1037-1047.

Wieczorek, A.J., Hekkert, M.P. 2012. Systemic instruments for systemic innovation problems: A framework for policy makers and innovation scholars. Science and Public Policy, 39, 74-87. 